\title{
CLASSIFICAÇÃO DE ROTAS DE ACESSO DE PEDESTRE DOS TERMINAIS DE TRANSPORTE COLETIVO AO CAMPUS DA UNIVERSIDADE CATÓLICA DE PERNAMBUCO.
}

\author{
LIRA, Luana Maria de Souza Veiga (1); \\ BAPTISTA, Arthur Henrique Neves (2) \\ (1) Universidade Católica de Pernambuco, Graduanda em Arquitetura e Urbanismo \\ e-mail:luanaveigalira@gmail.com \\ (2) Universidade Católica de Pernambuco, Doutor em Desenvolvimento Urbano \\ e-mail:arthurbap@gmail.com
}

\begin{abstract}
RESUMO
Esta pesquisa tem como objetivo classificar o nível de Acessibilidade Efetiva em três rotas a partir de pontos de transporte público até a Universidade Católica de Pernambuco (UNICAP). Como metodologia, foram aplicados procedimentos para obtenção dos níveis de Acessibilidade Efetiva do objeto de estudo e sua posterior classificação, analisando as possibilidades de realização da tarefa vivenciada pela pessoa numa abordagem ergonômica. Os resultados obtidos contribuem para definir diretrizes e futuras propostas ou intervenções em estruturas de circulação de pedestres seguindo os preceitos do Desenho Universal.
\end{abstract}

Palavras chave: Acessibilidade Efetiva, Calçadas, Desenho Universal, Pedestres.

\begin{abstract}
This research has the objective to classify the level of Effective Accessibility in three routes from points of public transportation to the Universidade Católica de Pernambuco (UNICAP). As a methodology, procedures were applied to obtain the levels of Effective Accessibility of the object of study and its subsequent classification, analyzing the possibilities of accomplishing the task experienced by the person in an ergonomic approach. The results obtained contribute to define guidelines and future proposals or interventions in structures of pedestrian circulation following the precepts of the Universal Design.
\end{abstract}

Keywords: Effective Accessibility, Sidewalks, Universal Design, Pedestrians.

\section{INTRODUÇÃO}

\subsection{Tema}

O referente artigo analisa a acessibilidade efetiva de pedestres no entorno da Universidade Católica de Pernambuco (UNICAP), localizada no bairro de Santo Amaro, Recife-PE. O intuito de pesquisa é classificar o nível de Acessibilidade Efetiva de estruturas de circulação de pedestres no acesso a UNICAP a partir dos terminais de transporte coletivo do entorno do campus. Diferentes tipos de usuários necessitam percorrer estruturas de circulação de pedestres realizando diferentes tarefas em diferentes contextos. Para garantir esse acesso é 


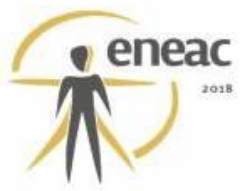

condição essencial um bom nível de Acessibilidade Efetiva destas estruturas, considerando as diversas habilidades e limitações dos pedestres.

A pesquisa em questão estuda três rotas, com início nas paradas de transporte público mais utilizadas pelos pedestres para ter acesso a UNICAP: a partir da Avenida Conde da Boa Vista, da Av. Visconde de Suassuna e da Rua do Príncipe. Ao ter conhecimento sobre o nível de Acessibilidade Efetiva dessas rotas de acesso ao campus, o pedestre tendo ou não alguma deficiência física ou visual poderá escolher qual rota lhe proporcionará maior conforto e segurança (ver figura 1).

Figura 1: Localização da Universidade Católica de Pernambuco (UNICAP) e rotas de estudo.

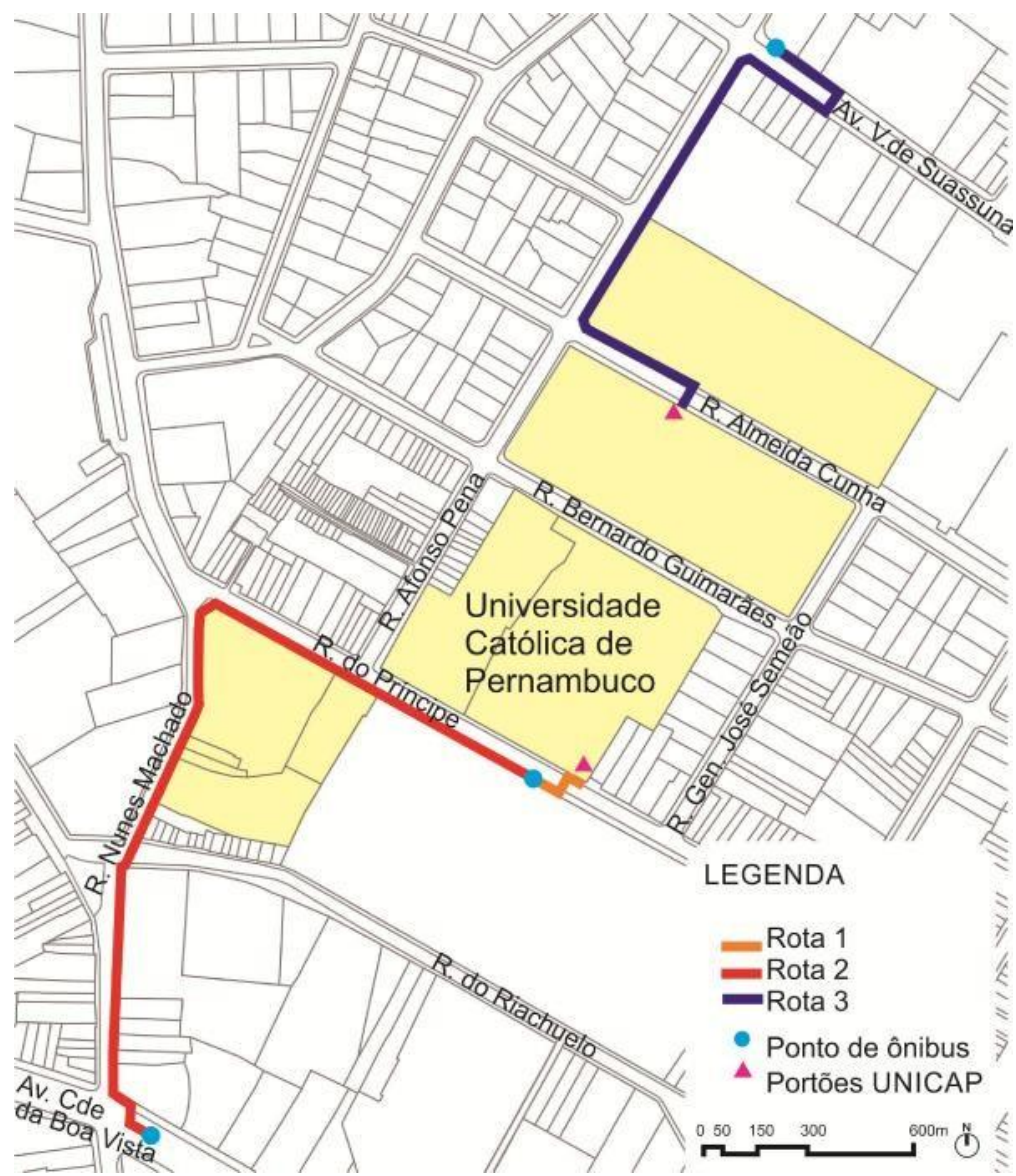

Fonte: Autores a partir de mapa base do ESIG (2016)

\subsection{Problema}

As pessoas se locomovem diariamente para resolver questões do cotidiano. Essa locomoção pode ser facilitada, caso o percurso seja preservado, o que nem sempre ocorre no entorno da UNICAP. Os trajetos realizados das paradas de transporte público ao campus, em geral, são mal conservados, apresentando obstáculos como desníveis e barreiras, além de superfícies com buracos ou danificadas por raízes expostas de árvores, entre outros. As dificuldades existentes prejudicam o acesso de um pedestre sem restrições, podendo inviabilizar o acesso de um usuário com deficiência. Contrária a atual realidade, uma rua bem projetada com calçadas conservadas pode ser mais atrativa aos olhos do cidadão, convidando a população ao passeio e permitindo interações sociais. 
Os três trajetos analisados na pesquisa possuem características semelhantes quanto às condições do passeio como espaços de passagem estreitos, superfícies desniveladas, o uso incorreto ou a falta de alegretes e interrupções na superfície das calçadas para facilitar a entrada de carros em garagens. Em todos os percursos é perceptível o estrangulamento das calçadas por árvores, mobiliário urbano, fiteiros, pontos comerciais, postes e placas que dificultam o acesso e aglomeração de pessoas em pontos de encontro e permanência. Diante do exposto, qual a experiência de acessibilidade que as pessoas vivenciam em cada segmento ao longo das rotas em estudo?

\subsection{Justificativa}

A UNICAP é protagonista no polo educacional da cidade e boa parte do corpo discente, docente e funcionários utilizam meios de transporte coletivo para acessar essa Instituição. Proporcionar uma boa Acessibilidade Efetiva nas estruturas de circulação de pedestres do seu entorno garante direitos iguais de acesso à educação para todos, beneficiando também as demais instituições de ensino, o comércio, a população local e o grande fluxo de pessoas que ali circulam.

De acordo com o censo demográfico de 2010 do Instituto Brasileiro de Geografia e Estatística (IBGE) cerca de 45,6 milhões de pessoas (23,9\% da população total) apresentaram pelo menos uma das deficiências investigadas no Brasil, incluindo severas, moderadas e leves. Revelando assim, a demanda por adequações nas estruturas de circulação com a finalidade de absorver esse contingente da população, oferecendo melhores condições durante o passeio. Portanto, se faz necessário um estudo da Acessibilidade Efetiva, contribuindo para uma requalificação, de modo que qualquer tipo de pedestre possa se deslocar sem dificuldades.

\subsection{Objetivos}

O objetivo geral é classificar o nível de Acessibilidade Efetiva de estruturas de circulação de pedestres no acesso a UNICAP a partir dos terminais de transporte coletivo do entorno do campus. Os objetivos específicos são:

- Identificar as rotas de acesso entre os terminais e os portões de acesso à UNICAP;

- Reconhecer as dificuldades enfrentadas por pedestres ao caminhar deambular nestas estruturas de circulação de pedestres;

- Avaliar os níveis de Acessibilidade Efetiva nas estruturas de circulação de pedestres identificadas;

- Elaborar quadro com diretrizes dimensionais para realizar futuras propostas e intervenções em estruturas de circulação de pedestres.

\section{CONCEITUAÇÃO TEÓRICA}

A Acessibilidade Efetiva é definida como a experiência de acessibilidade vivenciada por um sistema Acessante (pessoa) ao acessar um sistema Acessado (Arquitetura), executando ações de uma tarefa, em um dado contexto sob a influência de fatores de conveniência (BAPTISTA, 2010). A Teoria da Acessibilidade Efetiva (TAE) é um sistema que reuni constructos, relações, proposições, modelos e procedimentos metodológicos que visam descrever, explicar, aferir e predizer a experiência efetiva de acessibilidade. 
A teoria pode ser usada tanto como um procedimento de avaliação pós-ocupação, como para simulação de projetos, e assim visar à concepção de soluções de compromisso com a melhor relação custo $\mathrm{x}$ benefício ou um projeto integralmente universal. Logo, para afirmar se um ambiente é acessível ou não é necessário considerar a tarefa, o indivíduo acessante e o contexto.

O estudo da Acessibilidade Efetiva se distingue dos demais estudos da acessibilidade do ambiente construído por, ao invés de verificar o cumprimento ou não de uma conformidade da normativa técnica de acessibilidade, analisa as possibilidades de realização da tarefa, numa abordagem ergonômica, avaliando a acessibilidade efetivamente vivenciada pela pessoa. O entendimento é que a Acessibilidade Efetiva só pode ser conhecida se for compreendida como resultado das interações entre: [1] as aptidões de um elemento Acessante; [2] as exigências das atividades realizadas; [3] a configuração do elemento Acessado; [4] e o contexto circunstancial em que este se encontra; [5] todo sob a influência de fatores de conveniência. Estes elementos conformam um Sistema Acessante -Tarefa Acessado (SATA) que se altera a cada mudança circunstancial e recebe a influência externa de conveniências atrativas ou repulsivas.

Para que uma cidade seja inclusiva é necessário projetá-la seguindo conceitos de Ergonomia e do Desenho Universal. Assim, torna-se possível gerar rotas acessíveis para todo tipo de pessoa, sem limitá-las apenas a um tipo padrão de homem. A Teoria da Acessibilidade Efetiva surge nesse contexto como forma de avaliar e obter resultados a cerca do nível de acessibilidade da calçada para diferentes tipos de pedestres, auxiliando posteriormente, na elaboração de diretrizes que visam melhorias para todos.

Para se permitir a sensação de conforto espacial, torna-se primordial agir em prol da mobilidade inclusiva, da qualidade das calçadas e demais superfícies de deslocamento (NÓBREGA; CÂMARA, 2011). Deve-se ainda levar em consideração uma implantação coerente do mobiliário urbano e da vegetação. Afinal, uma condição importante para uma caminhada agradável é um espaço relativamente livre e desimpedido, sem necessidade de se desviar ou ser empurrado pelos outros (GEHL, 2010).

O intuito é contribuir por meio de intervenções, visando a implantação de Antropovias ou rotas acessíveis a todos (BAPTISTA, 2003). A construção de Antropovias em estruturas de circulação de pedestres considera a diversidade de pessoas e está dentro das prerrogativas do Desenho Universal. O Desenho Universal é uma filosofia de projeto que visa atender uma ampla gama da população sem a necessidade de projetos especializados (CAMBIAGHI, 2013; MACE et al., 1998).

O Brasil possui uma Norma técnica de Acessibilidade (NBR 9050), sua primeira versão de 1985 e a segunda de 1994 focavam apenas em pessoas com deficiência. Em sua terceira versão em 2004, é incorporado o termo Desenho Universal. Neste mesmo ano, surge o Decreto № 5.296 que regulamenta a Lei no 10.048 e a Lei oㅜ 10.098, e também incorpora 0 termo Desenho Universal. Hoje, a NBR 9050, está na sua quarta versão desde 2015, e a tônica do Desenho Universal foi ampliada. Sendo, portanto uma política pública.

\section{PROCEDIMENTOS METODOLÓGICOS}

Foram aplicados os procedimentos metodológicos para obtenção dos níveis de Acessibilidade Efetiva do objeto de estudo e sua posterior classificação. Com base nestes níveis será possível definir diretrizes para futuras propostas e intervenções na construção de Antropovias visando um Desenho Universal.

Para o cumprimento dos objetivos foram desenvolvidas as seguintes etapas:

- Reconhecimento da diversidade de habilidades, limitações e necessidades humanas 


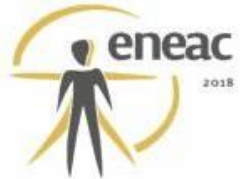

para o desenvolvimento de projetos arquitetônicos, paisagísticos e urbanísticos inclusivos com base na filosofia e princípios do Desenho Universal, critérios ergonômicos, parâmetros antropométricos e exigências normativas, através de pesquisa bibliográfica;

- Capacitação nos procedimentos metodológicos através da bibliografia adotada e de experimentos pilotos realizados em campo;

- Levantamento de campo, com registro fotográfico visando à delimitação das rotas de acesso entre os terminais e os portões de acesso a UNICAP que serão avaliadas no objeto de estudo;

- Coleta de dados quantitativos (dimensões, inclinações, quantidades,...) e qualitativos (estados de conservação, ambiência, acabamentos, conformidades,...) utilizando instrumentos adequados;

- Preenchimento da planilha de avaliação da Acessibilidade Efetiva, conforme prerrogativas da TAE;

- Confecção de mapas e relatórios com os resultados obtidos;

- Com base nos resultados obtidos, sugestão de diretrizes dimensionais para a melhoria do nível de Acessibilidade Efetiva.

\subsection{Construção de Indicadores da Acessibilidade Efetiva}

Quanto à delimitação do sistema acessado, a pesquisa engloba o percurso de três pontos de transporte coletivo até a UNICAP, escolhidos pela proximidade com o campus e maior quantidade de usuários (ver figura 1). No estudo são analisados três diferentes tipos de sistema Acessante (pedestres hipotéticos definidos para fins da pesquisa): ambulante, cadeirante e cego. Para cada sistema são analisados duas tarefas e dois contextos: a passeio em um horário normal (só barreiras fixas) e a trabalho em um horário de pico (barreiras fixas e móveis). Como delimitação da pesquisa foram concentrados os esforços nas questões de espaço e superfície. Dessa forma, pode-se obter a Acessibilidade Efetiva (espaço e superfície) para três tipos de usuários com perfis de locomoção diferentes e num contexto mais ameno, a passeio e outro em horário com maiores conflitos, a trabalho.

Ao deambular pela calçada, o sistema Acessante (pedestre) encontrará diferentes tipologias, como por exemplo, faixa de pedestres, corredores, manobras, entre outros. Cada tipologia apresenta um perfil de exigência diferente para cada usuário de acordo com suas limitações, repercutindo na definição do nível de Acessibilidade Efetiva. As delimitações no percurso foram feitas a cada mudança de tipologia. Os dados foram coletados a partir de observações em loco e preenchimento dos mesmos em planilha. A coleta de dados foi realizada a cada trecho, levando em consideração os tipos (seção transversal, seção longitudinal e manobra). Na planilha de campo foram utilizados Indicadores divididos em análise de espaço e de superfície. Os indicadores de espaço são: Altura Livre (AL) das calçadas, Batente Isolado (BI), Diâmetro de Manobras (DM) e Largura Livre (LL). Todos tem como unidade de medida o centímetro. Os indicadores de superfície: Desnível Simples (DS), Inclinação Longitudinal (IL), Inclinação Transversal (IT), Superfície Livre (SL), Superfície de Manobra (SM) e Superfície Regular (SR). Sendo esta aferida a partir de pontuação de 1 a 10, a Inclinação Longitudinal e Transversal medidas em porcentagem e as demais em centímetros. Em seguida é analisado o contexto, definindo valores para positivo ou negativo (ver quadro 1). 
Quadro 1 - Planilha de campo

\begin{tabular}{|c|c|c|c|c|c|c|c|c|c|}
\hline & & & Planilha & deca & $m p o$ & & & & Folha \\
\hline & & Código & & & & & Cont & texto & \\
\hline & Percurso & tipo & número & $s$ & 4 & Anula & & & Ohsenar̃̃es \\
\hline & & & & & & Anuld & Positivo & Negativo & Udservaçoes \\
\hline & & licado & & & & & & & \\
\hline & Altura Li & & & $\overline{\mathrm{AL}}$ & $\mathrm{cm}$ & $>300$ & & & \\
\hline & Batente & solad & & $\mathrm{BI}$ & $\mathrm{cm}$ & 0 & & & \\
\hline Espaço & Diametrc & ode $M$ & lanobra & $\mathrm{DM}$ & $\mathrm{cm}$ & $>300$ & & & \\
\hline & Largura L & ivre & & $\mathrm{LL}$ & $\mathrm{cm}$ & $>300$ & & & \\
\hline & Desnivel & Simpl & & DS & $\mathrm{cm}$ & 0 & & & \\
\hline & Inclinaçã & LLon & gitudinal & $\mathrm{IL}$ & $\%$ & 0 & & & \\
\hline & Inclinaçã & oTrar & nsversal & IT & $\%$ & 0 & & & \\
\hline Superfície & Superfíci & e Livr & & $S L$ & $\mathrm{~cm}$ & $>300$ & & & \\
\hline & Superfíci & e Mar & nobra & SM & $\mathrm{cm}$ & $>300$ & & & \\
\hline & Superfíci & Reg & zular & SR & $\begin{array}{c}0- \\
10\end{array}$ & 10 & & & \\
\hline
\end{tabular}

Fonte: Autores (2017)

As três rotas foram analisadas isoladamente, sendo fracionadas em segmentos, definidos a cada alteração substancial na configuração da calçada. Assim, foi possível avaliar os níveis de Acessibilidade Efetiva de cada segmento das calçadas de acordo com a tabela de Associação de cores e níveis de Acessibilidade Efetiva (ver quadro 2). Cada alteração no nível de Acessibilidade Efetiva, altera a cor do espectro, variando do "ultravioleta" para o acesso pleno ao "infravermelho", representado com a cor preta, para o Acesso nulo (BAPTISTA, 2010). A tabela possui cores para auxiliar didaticamente a compreensão das análises de conforto e segurança no acesso de cada segmento. As informações de cada seguimento foram preenchidas na planilha de campo e posteriormente na planilha de resultados, obtendo a cor que indica o nível de Acessibilidade Efetiva de cada trecho (ver exemplo no quadro 3).

A avaliação foi realizada através da planilha de verificação da Acessibilidade Efetiva e os mapas foram elaborados a partir do cruzamento dos resultados dos três Sistemas Acessantes, das duas Tarefas e dos dois contextos, sendo possível verificar através de cores os níveis de Acessibilidade Efetiva de cada um dos segmentos. Cada segmento de calçada foi analisado minuciosamente, com o intuito de diminuir o grau de subjetividade da avaliação.

\section{Quadro 2 - Convenção de cores para representação do nível de Acessibilidade Efetiva}

\begin{tabular}{|c|c|c|c|c|c|c|c|}
\hline $\begin{array}{l}\text { Faixas do } \\
\text { Espectro de } \\
\text { Acessibilidade }\end{array}$ & $\begin{array}{l}\text { Ultra- } \\
\text { violeta }\end{array}$ & Azul & Verde & Amarela & Laranja & Vermelha: & $\begin{array}{c}\begin{array}{c}\text { Infra- } \\
\text { vermelha }\end{array} \\
\ldots . . .\end{array}$ \\
\hline $\begin{array}{c}\text { Acessibilidade } \\
\text { Efetiva }(x)\end{array}$ & $x>1,00$ & $0,80<x \leq 1,00$ & $0,60<x \leq 0,80$ & $0,40<x \leq 0,60$ & $0,20<x \leq 0,40$ & $0<x \leq 0,20$ & $x \leq 0$ \\
\hline & Acesso & \multicolumn{5}{|c|}{ Acesso possivel - intermediário } & \multirow{3}{*}{$\begin{array}{c}\text { Acesso } \\
\text { nulo }\end{array}$} \\
\hline Segurança & pleno com & Adequada & Boa & Razoàvel & Pouca & Sem & \\
\hline Conforto & excessos & Adequado & Bom & Razoável & Pouco & Sem & \\
\hline
\end{tabular}

Fonte: (BAPTISTA, 2010) 


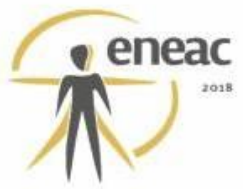

Quadro 3 - Planilha de resultados por trecho (Exemplo Rota 01)

\begin{tabular}{|c|c|c|c|c|c|c|c|c|c|c|c|c|c|c|c|c|c|}
\hline \multicolumn{6}{|c|}{ Usuário 1 -Ambulante } & \multicolumn{6}{|c|}{ Usuário 2-Cadeirante } & \multicolumn{6}{|c|}{ Usuário 3-Cego } \\
\hline \multicolumn{2}{|c|}{ Passeio } & \multirow{2}{*}{ Nivel } & \multicolumn{2}{|c|}{ Trabalho } & \multirow{2}{*}{ Nivet } & \multicolumn{2}{|c|}{ Passcio } & \multirow{2}{*}{ Nívtel } & \multicolumn{2}{|c|}{ Trabalho } & \multirow{2}{*}{ Nivel } & \multicolumn{2}{|c|}{ Passcio } & \multirow{2}{*}{ Nivtel } & \multicolumn{2}{|c|}{ Trabulno } & \multirow{2}{*}{ Nívte } \\
\hline c & E & & c & $\varepsilon$ & & c & $E$ & & c & E & & $c$ & $\mathrm{E}$ & & $c$ & E & \\
\hline 190 & 100 & 1 & 200 & 110 & 1 & 1.50 & 110 & 1 & $18 \mathrm{a}$ & 120 & 1 & 200 & 170 & 1 & 210 & 170 & 1 \\
\hline 0 & 60 & 1 & 0 & 30 & 1 & 0 & 5 & 1 & 0 & 3 & 1 & 0 & 30 & 1 & 0 & 20 & 1 \\
\hline 120 & 60 & 1 & 130 & 80 & 1 & 120 & 90 & 1 & 150 & 120 & 0,5 & 120 & 70 & 1 & 140 & 90 & 0,9 \\
\hline 100 & 40 & 1 & 110 & 50 & 1 & 100 & 80 & 1 & 120 & 85 & 1 & 100 & 60 & 1 & 120 & 70 & 1 \\
\hline 0 & 50 & 1 & 0 & 30 & 1 & o & 5 & 1 & o & 3 & 1 & 0 & 40 & 1 & 0 & 20 & 1 \\
\hline 5 & 30 & 1 & 5 & 20 & 1 & o & 12,5 & 1 & a & 8,33 & 1 & o & 20 & 1 & o & $17, .7$ & 1 \\
\hline 0 & 10 & 1 & 0 & $b$ & 1 & 0 & 4 & 1 & 0 & 2 & 1 & 0 & th & 1 & 0 & 2 & 1 \\
\hline 90 & 10 & 1 & 100 & 30 & 1 & 90 & 75 & 1 & 100 & 70 & 1 & 100 & 60 & 1 & 110 & 70 & 1 \\
\hline 100 & 50 & 1 & 120 & 60 & 1 & 110 & 80 & 1 & 140 & 90 & 0,6 & 120 & 60 & 1 & 150 & 80 & $0,5 / 143$ \\
\hline 8 & 1 & 1 & 9 & 3 & 0,83333 & 10 & 4 & 0,66667 & 10 & 5 & 0,6 & 9 & 3 & 0,83333 & 10 & 4 & 0,66667 \\
\hline \multicolumn{2}{|c|}{ Resulta } & 1 & Resul & & 0.83333 & Result: & & 0.66667 & Result & & 0,18 & Resul & & 0,83333 & \multicolumn{2}{|c|}{ Resultado } & 0,34286 \\
\hline
\end{tabular}

Fonte: Autores (2017)

\section{RESULTADOS E DISCUSSÃO}

Os resultados foram conseguidos a partir do levantamento de dados realizado em cada rota individualmente. Para obter os resultados a cerca da Acessibilidade Efetiva foram considerados três Sistemas Acessantes, duas Tarefas com dois contextos e 738 Sistemas Acessados. As rotas 02 (ver figuras 03 e 04) e 03 (ver Figuras 5 e 6) foram divididas em dois mapas para melhor visualização. A rota 02 tem início (saída da UNICAP) se sobrepondo a rota 1 (ver figura 2 ).

Figura 2 - Resultado das análises na Rota 1

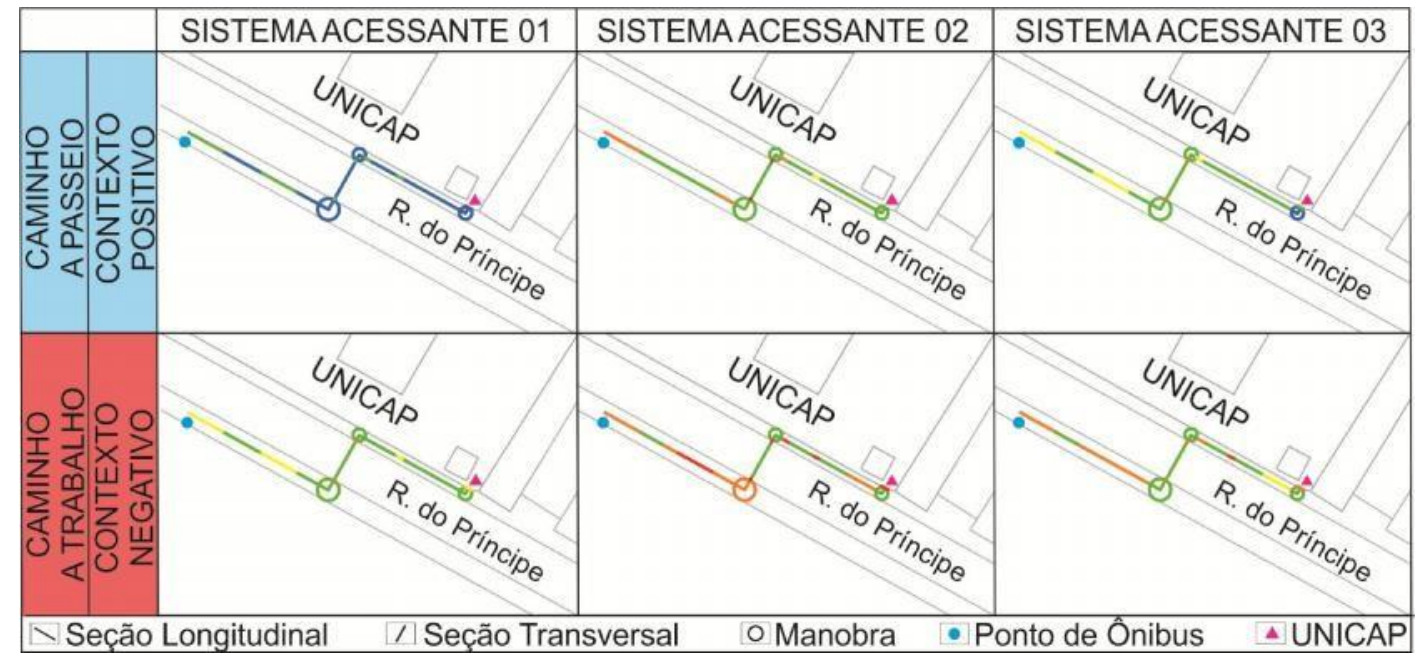

Fonte: Autores, a partir de mapa base do ESIG (2017)

\section{Rota 1: Caminho a Passeio no Contexto Positivo}

O Sistema Acessante 01 representado por um usuário comum, no contexto positivo atingiu os melhores resultados de Acessibilidade Efetiva. O Sistema Acessado apresenta espectro que varia entre o azul e o verde, denotando um sistema acessante com pouca ou nenhuma restrição, realizando uma tarefa simples em contexto positivo, o que sugeri conforto e segurança na caminhada. O Sistema Acessante 02 caracterizado como cadeirante e 0 Sistema Acessante 03 com deficiência visual possuem boa Acessibilidade Efetiva demonstrada pelo espectro na cor verde mas, alguns pontos com dificuldade de locomoção nas cores amarelo e laranja, por conta de aglomerado de pessoas e buracos nas calçadas. 


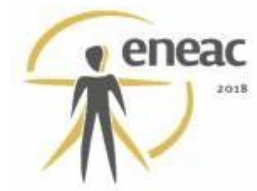

Rota 1: Caminho a Trabalho no Contexto Negativo

No contexto negativo o Sistema Acessante 01 apresentou trechos em amarelo devido a barreiras (fiteiro, aglomerado de pessoas, inclinação do terreno e piso irregular), configurando um nível razoável de Acessibilidade Efetiva. O Sistema Acessante 02 (cadeirante) apresentou maiores dificuldades nos trechos marcados em laranja e vermelho 0 que denota baixo nível de Acessibilidade Efetiva ocasionados pelo estreitamento da calçada, irregularidades do piso e ausência de rampas. O Sistema Acessante 03 realiza o caminho a trabalho com dificuldades como demonstram os trechos em laranja, devido ao aumento de pessoas no local, próximo ao ponto de ônibus e pela presença de irregularidades no piso.

\section{Rota 2: Caminho a Passeio no Contexto Positivo}

Esse percurso tem início na rota 1, tendo sua continuidade nos figuras 3 e 4 . Essa rota se caracteriza por ser longa, apresentando dificuldades para todos os sistemas acessantes, sendo mais favorável ao Sistema Acessante 01. Para o usuário comum boa parte do percurso se caracteriza nas cores azul, verde e amarelo, o que sugere razoável dificuldade ao caminhar. Os Sistemas Acessantes 02 e 03 apresentam segmentos com baixo nível de Acessibilidade Efetiva, representados pela cor laranja, o que ocorre devido ao estreitamento da calçada pela presença de raízes expostas das árvores. Ambos possuem trechos com acessibilidade razoável demonstrados com a cor amarela, tendo o Sistema 03 um longo trecho em verde denotando um bom desempenho da Acessibilidade Efetiva.

\section{Rota 2: Caminho a Trabalho no Contexto Negativo}

O percurso realizado a trabalho apresentou mais trechos com barreiras. Os Sistemas Acessantes 01 e 02 possuem alguns trechos em laranja o que reduz consideravelmente a locomoção. O Sistema 01 apresenta trechos com razoável acessibilidade, nas cores amarelo e verde. No Sistema 02 trechos em vermelho denotam espaços estreitos ou superfícies muito irregulares que inviabilizam a passagem de cadeirantes. O Sistema Acessante 03 apresenta baixo nível de acessibilidade, tendo pontos críticos na R. Afonso Pena por conta das raízes expostas das árvores e próximo à Av. Conde da Boa Vista pelo piso desgastado demonstrado com o espectro laranja.

Figura 3 - Resultado das análises na Rota 2, trecho 1

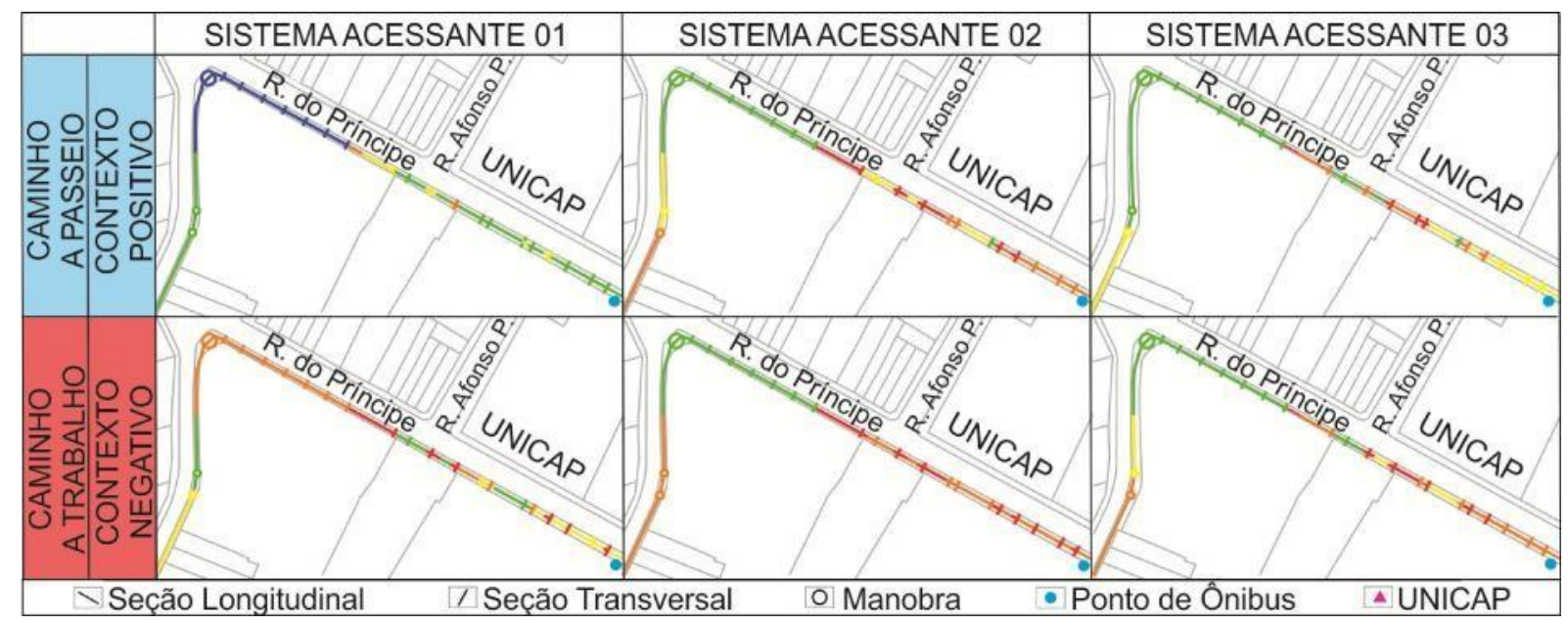

Fonte: Autores, a partir de mapa base do ESIG (2017) 


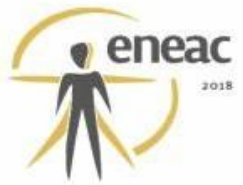

Figura 4 - Resultado das análises na Rota 2, trecho 2

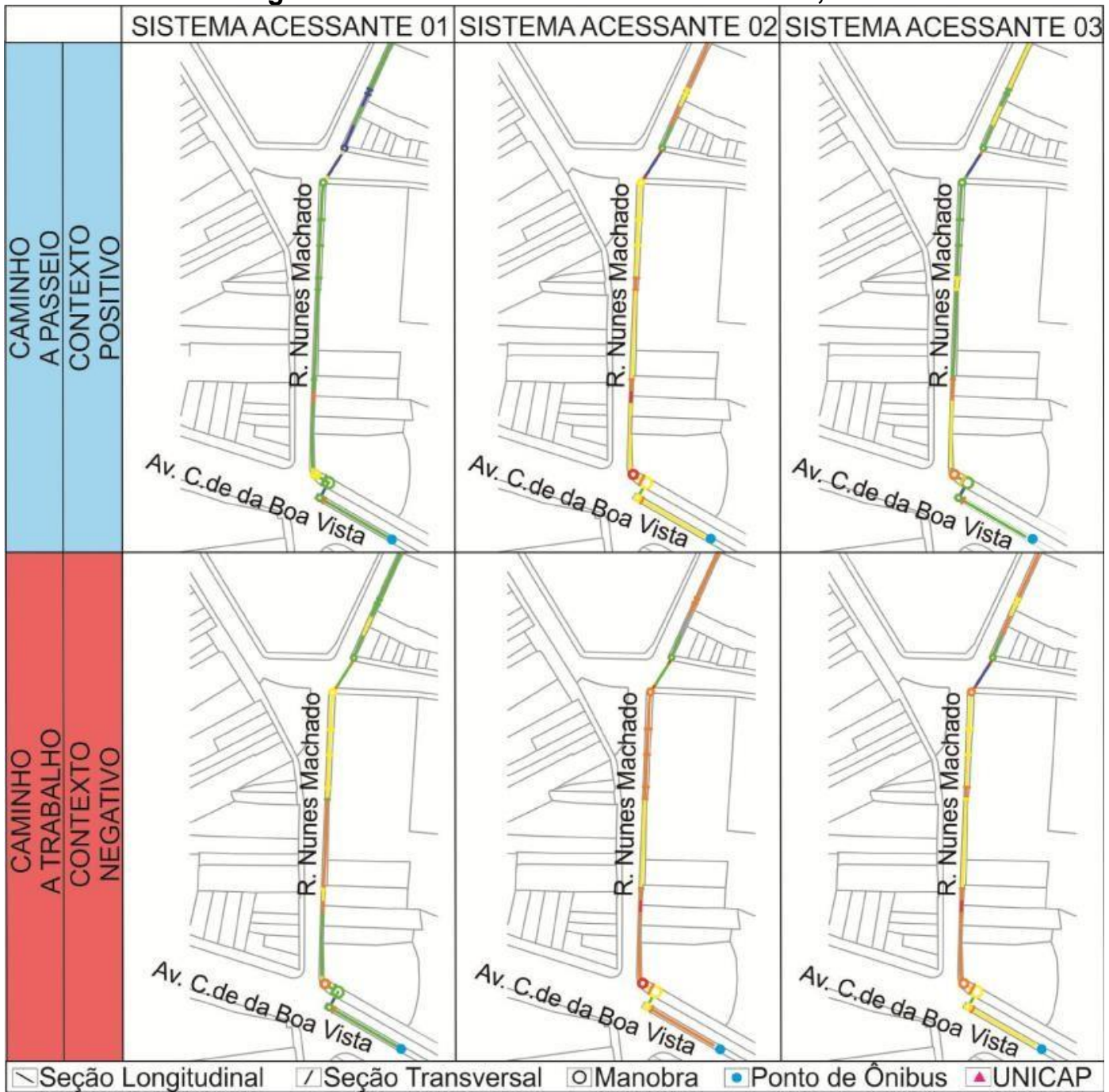

Fonte: Autores, a partir de mapa base do ESIG (2017)

Rota 3: Caminho a Passeio no Contexto Positivo

Apresenta dificuldades de acesso para todos os Sistemas Acessantes. A locomoção é comprometida na R. Afonso Pena e na R. Almeida Cunha por inclinações abruptas nas entradas de garagens e pelos estreitamentos nas calçadas devido à presença de árvores com raízes expostas. Na Av. Vde. de Suassuna, o fluxo de pessoas é prejudicado pelo comércio ambulante, embora suas calçadas sejam as mais largas e conservadas, oferecendo maior segurança e conforto. O Sistema Acessante 01 apresenta boa Acessibilidade Efetiva demonstrado pelo espectro verde. Para os Sistemas Acessantes 02 e 03 , alguns trechos possuem dificuldade média demonstrados nas cores amarelo e laranja.

Rota 3: Caminho a Trabalho no Contexto Negativo

O Sistema Acessante 01 apresenta razoável dificuldade em trechos amarelos e laranjas. Para o Sistema Acessante 02 muitos trechos são inviáveis devido ao estreitamento da calçada e irregularidade do piso, demonstrados nas cores laranja e vermelho. O Sistema Acessante 03 apresenta muita dificuldade no caminho a trabalho, com espectros em sua maioria vermelhos denotando um percurso sem conforto ou segurança. 


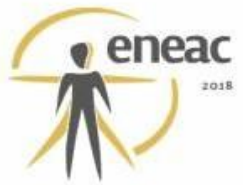

Figura 5 - Resultado das análises na Rota 3, trecho 1

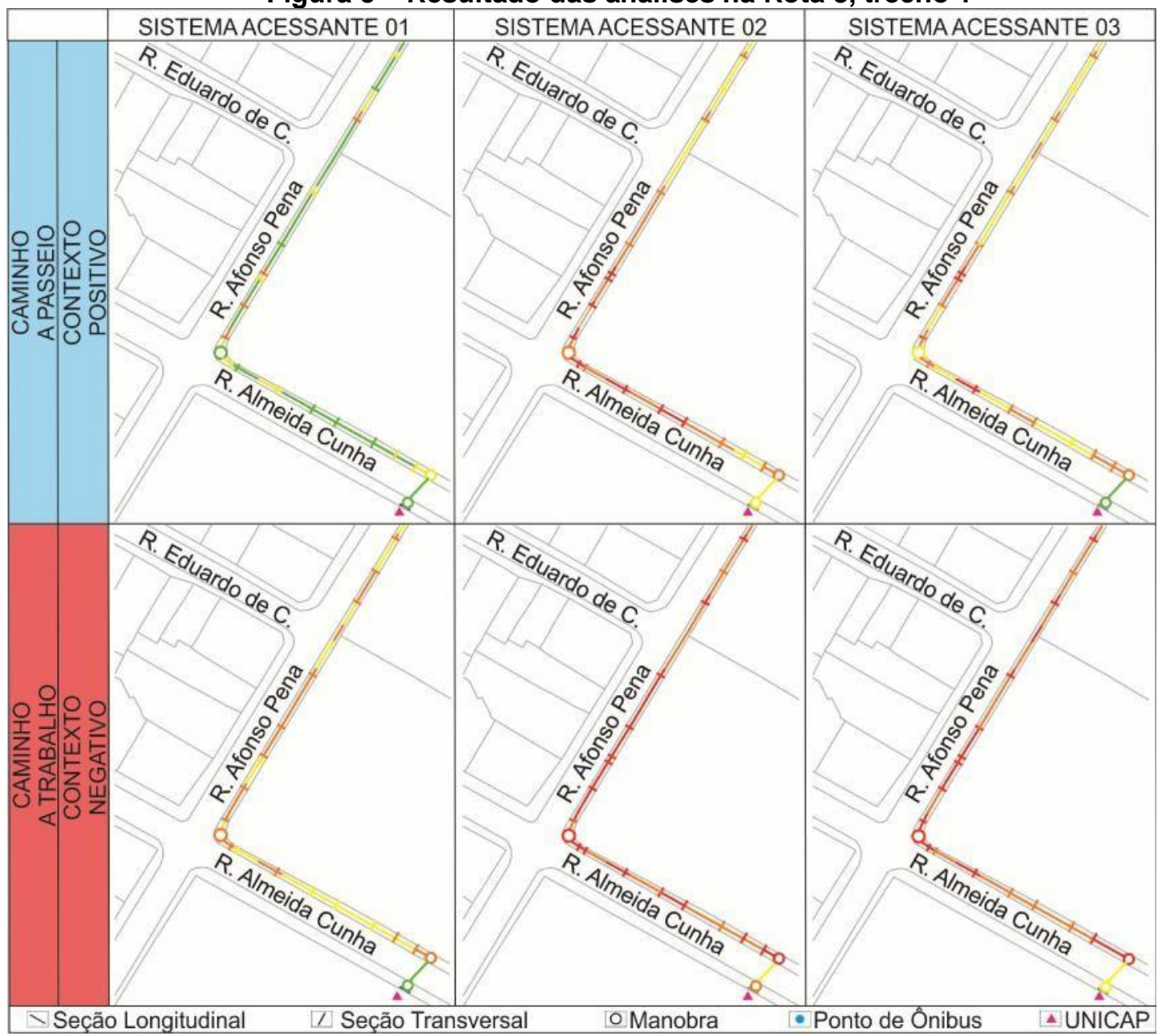

Fonte: Autores, a partir de mapa base do ESIG (2017)

Figura 6 - Resultado das análises na Rota 3, trecho 2

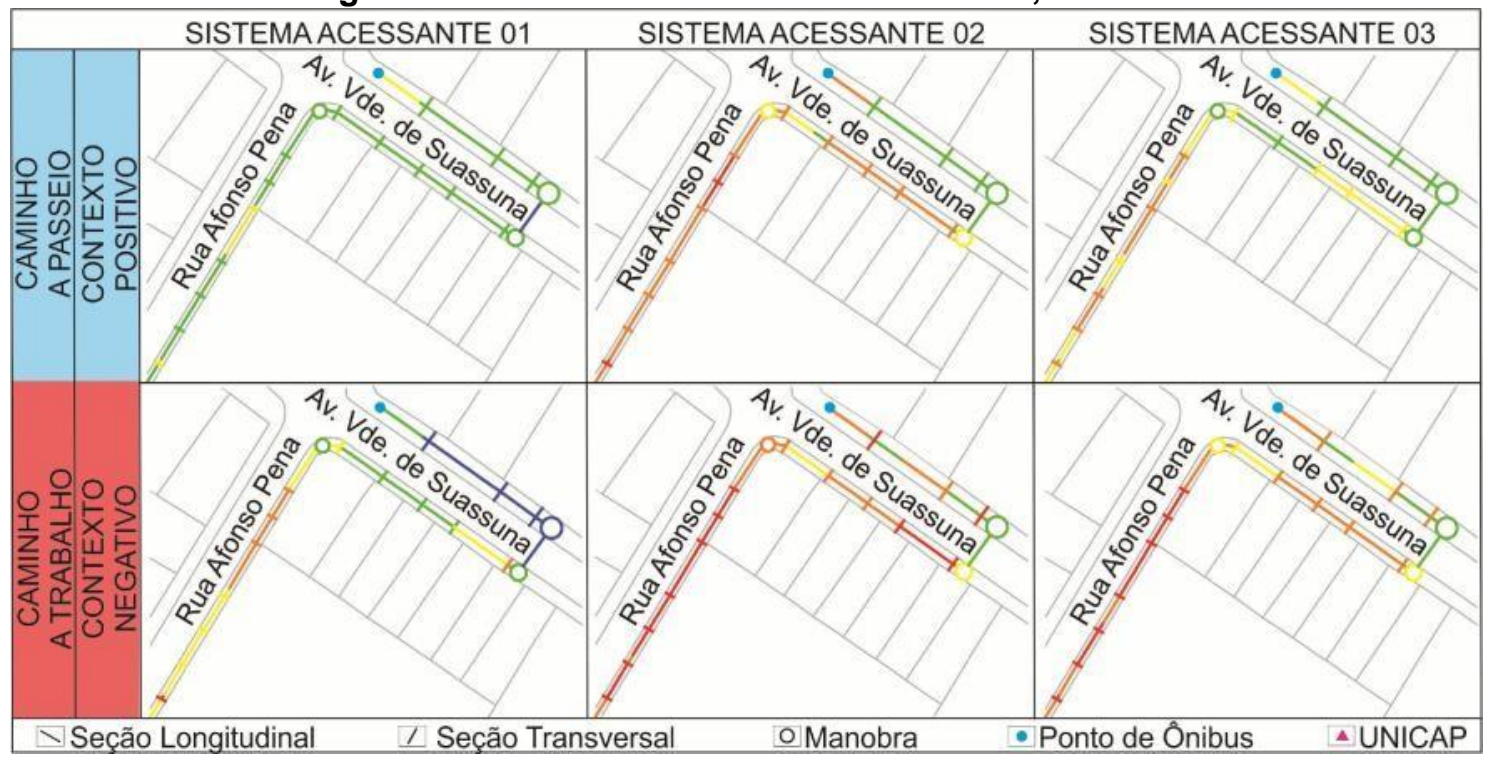

Fonte: Autores, a partir de mapa base do ESIG (2017) 
Avaliando todas as interações, o Sistema Acessante 01 possui melhores níveis de Acessibilidade Efetiva para as três rotas por possuir facilidade de locomoção. O sistema acessante 02 e 03 , com deficiências físicas e visuais respectivamente apresentaram maior dificuldade de circulação. As dificuldades demonstram um grande número de barreiras intermitentes que aparecem durante os percursos. Por possuir menor incidência das mesmas, a rota 01 é a mais indicada para os três Sistemas Acessantes. Seria necessário ainda melhorar pontos críticos da mesma, para garantir acessibilidade, como por exemplo, a implantação de rampa com piso tátil na travessia da Rua do Príncipe (ver figura 9 e 10).

Para que um segmento possa ser considerado acessível pelos três Sistemas Acessantes nos dois contextos estudados, seria necessário uma combinação de indicadores ideais que servem como diretrizes dimensionais para realizar futuras propostas e intervenções em estruturas de circulação de pedestres (ver quadro 4). Lembrando que um bom dimensionamento é necessário, mas não é o suficiente, devendo-se ater aos demais princípios do Desenho Universal para se alcançar uma acessibilidade plena.

Quadro 4 - Diretrizes dimensionais

\begin{tabular}{|c|c|c|c|c|c|c|c|c|c|}
\hline \multicolumn{4}{|c|}{ Espaço } & \multicolumn{6}{|c|}{ Superfície } \\
\hline$A L$ & $\mathrm{BI}$ & DM & LL & DS & IL & IT & SL & SM & SR \\
\hline 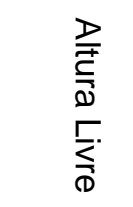 & 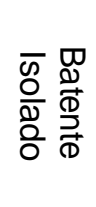 & 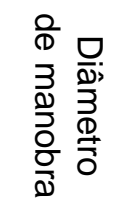 & 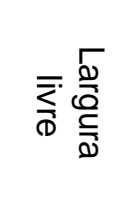 & 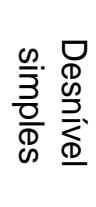 & 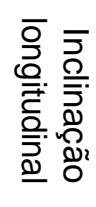 & 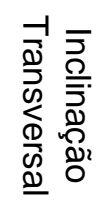 & 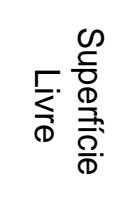 & 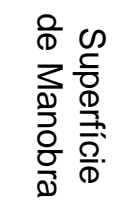 & 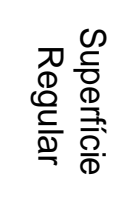 \\
\hline $\begin{array}{c}\text { Min. } \\
210 \mathrm{~cm}\end{array}$ & Nulo & $\begin{array}{c}\text { Min. } \\
150 \mathrm{~cm}\end{array}$ & $\begin{array}{c}\text { Min. } \\
120 \mathrm{~cm}\end{array}$ & Nulo & Nulo & Nulo & $\begin{array}{c}\text { Min. } \\
120 \mathrm{~cm}\end{array}$ & $\begin{array}{c}\text { Min. } \\
150 \mathrm{~cm}\end{array}$ & $\begin{array}{l}\text { Estável/ } \\
\text { Regular }\end{array}$ \\
\hline
\end{tabular}

Fonte: Autores

Figura 7 - Trecho da Rota 1

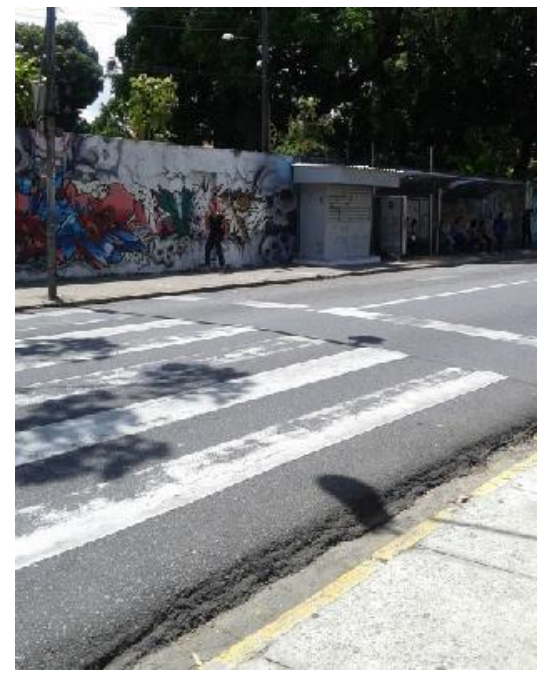

Fonte: Autores (2017)
Figura 8 - Proposta para Rota 1

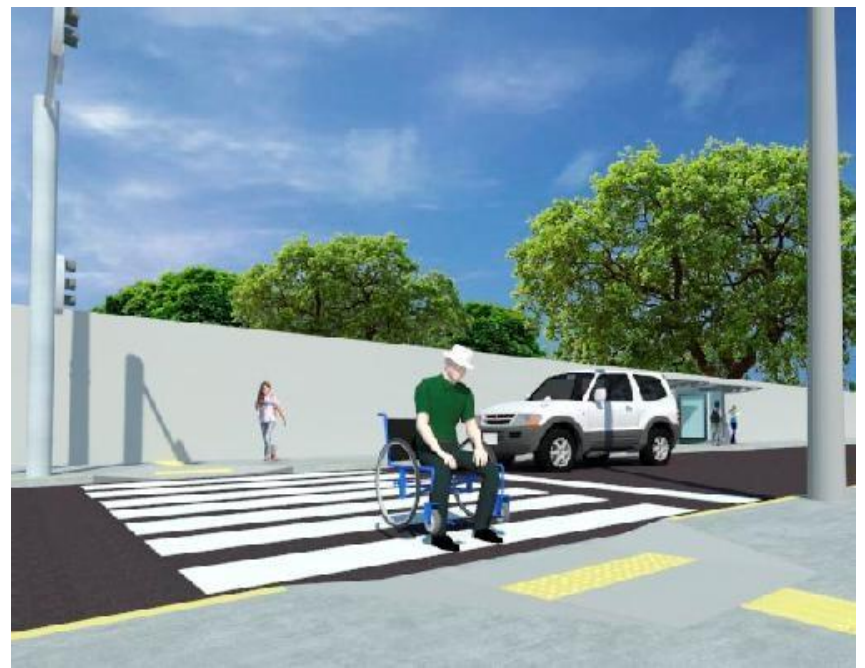

Fonte: Autores (2017) 


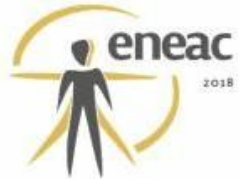

\section{CONCLUSÃO}

A pesquisa propôs avaliar as condições de acesso do percurso de pontos de transporte público até a UNICAP, tendo como base a Teoria de Acessibilidade Efetiva e conceitos de Ergonomia e de Desenho Universal. A partir das análises e dos resultados obtidos foi possível avaliar os níveis de Acessibilidade Efetiva das três rotas e analisar os conflitos para cada Sistema Acessante.

A partir desses resultados foi possível elaborar um quadro com indicadores que sugerem Acessibilidade Efetiva para os três Sistemas Acessantes estudados. Essa proposta visa facilitar a elaboração de diretrizes que garantirão o deslocamento de uma ampla gama de usuários. Os resultados podem ainda ser divulgados ao público, para que o mesmo possa acessar o campus de forma mais segura e confortável escolhendo sua rota.

\section{REFERÊNCIAS}

ASSOCIAÇÃO BRASILEIRA DE NORMAS TÉCNICAS - ABNT. NBR 9050; Acessibilidade de pessoas portadoras de deficiências a edificações, espaço, mobiliário e equipamentos urbanos. Rio de Janeiro: ABNT, 2015.

BAPTISTA, A. H. N. Procedimentos metodológicos para a avaliação da acessibilidade de estruturas de circulação de pedestre com vistas ao projeto de "Antropovias".2003, 142p. Dissertação (mestrado em Engenharia de Produção) Universidade Federal de Pernambuco. Recife: o autor, 2003.

BAPTISTA, A. H. N. Proposição da Teoria da Acessibilidade Efetiva com plano de verificação para estruturas de circulação de pedestre. Tese (Doutorado em Desenvolvimento Urbano). Universidade Federal de Pernambuco, Recife: o autor, 2010.

BAPTISTA, A. H. N. Planilha para experimentos de Acessibilidade Efetiva em estruturas de circulação de pedestres, III Encontro Nacional de Ergonomia do Ambiente Construído e IV Seminário Brasileiro de Acessibilidade Integral, João Pessoa, 2011.

BRASIL. Decreto-Lei 5.296. Regulamenta as Leis nos 10.048, de 8 de novembro de 2000, que dá prioridade de atendimento às pessoas que especifica, e 10.098, de 19 de dezembro de 2000, que estabelece normas gerais e critérios básicos para a promoção da acessibilidade das pessoas portadoras de deficiência ou com mobilidade reduzida, e dá outras providências. 02 de dezembro de 2004.

CAMBIAGHI, S. Desenho Universal. Métodos e Técnicas para Arquitetos e Urbanistas. 3 ed. São Paulo: Senac, 2013.

GEHL, J. Cidades para Pessoas. São Paulo: Perspectiva, 2010.

MACE, R. L.; STORY,M. F.; MUELLER, J. L. The Universal Design file; designing for people of all ages and abilities. Raleigh: North Carolina StateUniversitySchoolof Design, 1998.

MORAES, A. M. de MONT ALVÃO, C. Ergonomia; conceitos e aplicações. $3^{a}$ ed. Rio de Janeiro: Ed. iUsEr, 2003.

NÓBREGA, M. L. C. C.; CÂMARA, C. D. D. Pela Coexistência Urbana: Estratégias de Planejamento para os Espaços Públicos Viários. Cadernos de Pós-Graduação em Arquitetura e Urbanismo. São Paulo: Ed Mackenzie, 2011. 